\title{
Childhood attention problems and socioeconomic status in adulthood: 18-year follow-up
}

Cédric Galéra, Manuel-Pierre Bouvard, Emmanuel Lagarde, Grégory Michel, Evelyne Touchette, Eric Fombonne and Maria Melchior

\section{Background}

Attention-deficit hyperactivity disorder (ADHD) has been associated with socioeconomic difficulties later in life. Little research in this area has been based on longitudinal and community studies.

\section{Aims}

To examine the relationship between childhood attention problems and socioeconomic status 18 years later.

\section{Method}

Using a French community sample of 1103 youths followed from 1991 to 2009, we tested associations between childhood attention problems and socioeconomic status between ages 22 and 35 years, adjusting for potential childhood and family confounders.

\section{Results}

Individuals with high levels of childhood attention problems were three times more likely to experience subsequent socioeconomic disadvantage than those with low levels of attention problems (odds ratio 3.44, 95\% Cl 1.72-6.92).

This association remained statistically significant even after adjusting for childhood externalising problems, low family income, parental divorce and parental alcohol problems.

\section{Conclusions}

This longitudinal community-based study shows an association between childhood attention problems and socioeconomic disadvantage in adulthood. Taking into account ADHD and associated difficulties could help reduce the long-term socioeconomic burden of the disorder.

\section{Declaration of interest}

M.-P.B. received financial support for the organisation of scientific meetings and was also the main investigator in clinical trials for Shire and Lilly. In the UK, E.F. provided advice on the epidemiology and clinical aspects of autism to scientists advising parents, to vaccine manufacturers, and to several government committees between 1998 and 2001. since 2004 E.F. has been an expert advisor to vaccine manufacturers and the US Department of Health and Social Services with regard to the autism thiomersal (thimerosal) litigation.
Attention-deficit hyperactivity disorder (ADHD) is a behaviourally defined developmental condition with childhood onset and often symptomatic continuity throughout life. Its high prevalence of about $5 \%$ in youths and $2 \%$ in adults, plus its association with numerous negative outcomes, is the source of substantial burden in affected individuals, their families and society, with possible loss of workforce productivity. In particular, ADHD has been linked to a range of social and occupational difficulties, including academic underachievement, unstable employment, job inactivity and poor job performance, as well as low income and occupational status. ${ }^{1-10}$

At least two main issues should be underlined regarding the link between ADHD and socioeconomic attainment. First, as in other common mental health disorders, social causation and health selection phenomena may apply. ${ }^{11-13}$ When examining the link between ADHD and socioeconomic status, it is therefore crucial to consider a broad range of potential early confounders, which many previous studies in the field have failed to do. Notably, among family characteristics, parental socioeconomic status is related to children's psychological difficulties, making it a critical factor to take into account. ${ }^{14-16}$ In addition, parental psychopathological disorder and instability may confound the relationship between $\mathrm{ADHD}$ and subsequent socioeconomic status. ${ }^{13,17}$ Another set of possible early confounders are other frequently co-occurring childhood psychopathological conditions, including externalising and internalising problems, which are likely to contribute to later socioeconomic disadvantage and confound the link between ADHD and subsequent socioeconomic status. ${ }^{18,19}$ A second shortcoming is that existing findings often stem from longitudinal studies of clinic-referred children and adolescents with ADHD or from cross-sectional studies of adults with retrospective reports. Additional longitudinal populationbased surveys are needed to provide results that can be generalised to the community. In this study we test the hypothesis that attention problems in childhood and adolescence (ages 4-16 years) are associated with low socioeconomic status in adulthood (ages 22-35 years) independently from other factors (childhood psychopathology, low household income during childhood and family characteristics) in a community sample followed over an 18-year period.

\section{Method}

Data for this study came from two sources based in France: young adults participating in the Trajectoires épidémiologiques en population (TEMPO) study and their parents who were taking part in the Gaz-Electricite (GAZEL) cohort study. ${ }^{20,21}$ The latter study was set up in 1989 and included 20624 men and women aged 35-50 years, employed in the energy sector in a variety of occupations from manual worker to manager and living in France. Since study inception the participants have been followed yearly by means of self-report questionnaires. The TEMPO study was set up in 2009 among young adults (aged 22-35 years) who had taken part in a study of children's psychological problems and access to mental healthcare in 1991. The original sample of children surveyed in 1991 was selected from children aged 4-16 years whose parents were participants in the GAZEL study. The original sample $(n=2582)$ was stratified to match the socioeconomic and family size characteristics of French families in 
the 1991 census. $^{20,21}$ In 2009 we asked parents of youths who had taken part in the 1991 survey to forward the TEMPO study questionnaire to their son or daughter. Of the 2498 young people whose parents were alive and could be contacted, 16 had died since 1991 and 4 were too ill or disabled to answer. The overall response rate to the 2009 questionnaire was $44.5 \%(n=1103)$, which is comparable to response rates in other mental health surveys in France. Leading reasons for non-participation were failure to forward the questionnaire by the parent $(34.8 \%)$ or the young person's lack of interest $(28.5 \%)$. Those who did not respond were more likely to be male, to come from families that were divorced, to have had a lower socioeconomic background and have had parents who smoked tobacco and abstained from alcohol. Participants and non-participants did not vary with regard to parental depression or Child Behavior Checklist (CBCL) total scores. ${ }^{22}$ The unemployment rate among TEMPO study members is comparable to that of young adults in the general population of France. ${ }^{23}$ The TEMPO study was approved by the French national committee for data protection, the Commission Nationale Informatique et Liberté.

\section{Measures}

\section{Mental health at baseline}

The respondents' psychopathologic state was assessed in 1991 when their parents completed the CBCL. ${ }^{22,24}$ The French version of the CBCL was validated in previous clinical and epidemiological studies. ${ }^{25}$ This widely used tool includes 118 items on young people's behavioural problems in the preceding 6 months. Each problem item is coded from 0 to 2 . The CBCL makes it possible to construct empirically based scales (based on factor analyses that identify syndromes of co-occurring problem items) of internalising, externalising and attention problems (that is, hyperactivity and inattention symptoms). The internalising score (Cronbach's $\alpha=0.83$ ) was based on three syndrome subscales: anxious/depressed syndrome (13 items), withdrawn behaviour (8 items) and somatic complaints (11 items). The externalising score $(\alpha=0.84)$ was based on two syndrome subscales: aggressive behaviour (18 items) and rule-breaking behaviour (17 items). The attention problems scale $(\alpha=0.72)$ comprised the following items: 'cannot concentrate', 'daydreams', 'impulsive', 'cannot sit still', 'acts young', 'confused', 'stares blankly' and 'poor school work'. This scale has been shown to be a good predictor of ADHD diagnosis. ${ }^{26}$ We kept a single combined variable because factor analysis of the CBCL did not yield separate factors for inattention and hyperactivity-impulsivity. ${ }^{24}$ Data missing on each CBCL scale were imputed when less than a third of values were missing. We generated a dichotomous variable (high $v$. low symptom levels) by using the 90th percentile of the score distribution, which is the recommended cut-off level to differentiate 'cases' and 'non-cases' in community samples.

\section{Family characteristics}

Family data primarily came from parents' own yearly reports in the GAZEL study between 1989 and 2009. Income at baseline was divided into tertiles (high income $\geqslant € 31100$ per year; intermediate income $<€ 31100$ and $\geqslant € 23800$ per year; low income $<€ 23800$ per year). Parental separation or divorce (yes $v$. no) was reported in the yearly GAZEL questionnaire. Parental depression (yes $v$. no) was defined as at least two parental selfreports of depression in the yearly GAZEL study questionnaire or by TEMPO participants' reports of parental lifetime depression ascertained using a questionnaire adapted from the National Institute of Mental Health Family Interview for Genetic Studies (FIGS) ${ }^{27}$ Parental alcohol problems (high alcohol use present $v$. absent) were defined as at least two parental self-reports of high alcohol use in the yearly GAZEL study questionnaire $(\geqslant 21$ glasses of alcoholic drink per week in women, $\geqslant 28$ glasses of alcoholic drink per week in men) and TEMPO participants' reports of parental alcohol dependence were ascertained using a questionnaire adapted from the FIGS. ${ }^{27}$

\section{Socioeconomic status at follow-up}

Participants were asked to report their employment situation, occupational grade and educational attainment at the time of the study, as well as their employment stability and experience of unemployment in the previous 12 months. Measuring the socioeconomic position of young adults who are in transition between education and employment is challenging. ${ }^{28}$ In France, as in other countries, young adults are a heterogeneous population who face unemployment and job insecurity at higher rates than the rest of the population. ${ }^{29}$ In order to address this issue, we used a composite indicator of socioeconomic circumstances based on educational attainment and employment characteristics, as in other studies. ${ }^{15,30}$ We constructed an overall indicator of socioeconomic status combining educational attainment, occupational grade (high: executive or managerial position; intermediate: intermediate position such as associate administrative professional or technician; low: blue-collar or clerical position), 12-month employment stability and 12-month experience of unemployment, each coded 0-2. Correlations between the four components of our socioeconomic indicator ranged from 0.03 to 0.47 . To study associations between childhood attention problems and socioeconomic status, we divided the latter distribution into tertiles (high, intermediate and low status).

\section{Statistical analysis}

We first described sample characteristics and situation at follow-up by level of attention problems at study baseline. We then sought to estimate the strength of the association between childhood attention problems and socioeconomic status 18 years later, controlling for potential confounders and restricting the study sample to participants who were on the labour market (students, who by definition had not completed their education, were excluded from the sample). Analyses were therefore performed using multinomial logistic regression models adjusted for gender (male $v$. female), age (continuous), family income (low $v$. high and intermediate $v$. high), parental divorce (yes $v$. no), parental depression (yes $v$. no), and high parental alcohol use (yes $v$. no). To select predictors included in the final regression model, we first estimated age- and gender-adjusted relationships between independent variables and the outcome (Wald $\chi^{2} /$ twotailed analyses). Variables with $P<0.25$ were entered into the initial regression models. Backwards selection (variables deleted when $P>0.05$ ) with control for confounding factors was then conducted. Finally, we tested relevant interactions between attention problems and all explanatory variables kept in the final model. Multicollinearity was tested using the Belsley criteria. To test the robustness of the findings, several sensitivity analyses were conducted. Data were reanalysed as follows:

(a) adjusting for prior school difficulties (indexed as more than one grade retention $v$. one or no grade retention);

(b) modifying the attention problems variable by dropping the item 'poor school work' from the attention problems scale;

(c) coding $\mathrm{CBCL}$ scores as $z$-standardised scores;

(d) modifying the socioeconomic status composite indicator by dropping educational attainment from the socioeconomic status construct. 
Statistical significance was determined at a level of $P<0.05$. All calculations were carried out using SAS version 9.1 for Windows (SAS Institute, Cary, North Carolina, USA).

\section{Results}

Table 1 lists the main sociodemographic features of the sample. Table 2 shows participants' situation at follow-up and socioeconomic status according to level of attention problems at study baseline. Participants with high levels of such problems were more often unemployed or out of the labour market, and had lower occupational grade, educational attainment and socioeconomic status than their counterparts with low problem levels. Table 3 provides the results of regression analyses for socioeconomic status at follow-up. The multivariate model $(n=950)$ was significant (Wald $\chi^{2}=111.43, P<0.0001$ ). Attention problems, externalising problems, low income at baseline, parental divorce and parental alcohol problems were significantly related to lower socioeconomic status 18 years later. There was no significant interaction between attention problems and gender. Sensitivity analyses conducted adjusting for prior school difficulties, dropping the item 'poor school work' from the attention problems scale, using standardised CBCL scores and dropping educational attainment from the socioeconomic status variable yielded results consistent with our main findings (not shown).

\section{Discussion}

In this longitudinal French community-based study, attention problems in childhood and adolescence were associated with lower socioeconomic status in young adulthood. This association was driven by lower occupational grade, lower educational achievement and to a lesser extent by higher unemployment. Importantly, this association remained even after we accounted for childhood externalising problems and family risk factors including low household income and parental history of divorce and alcohol problems.

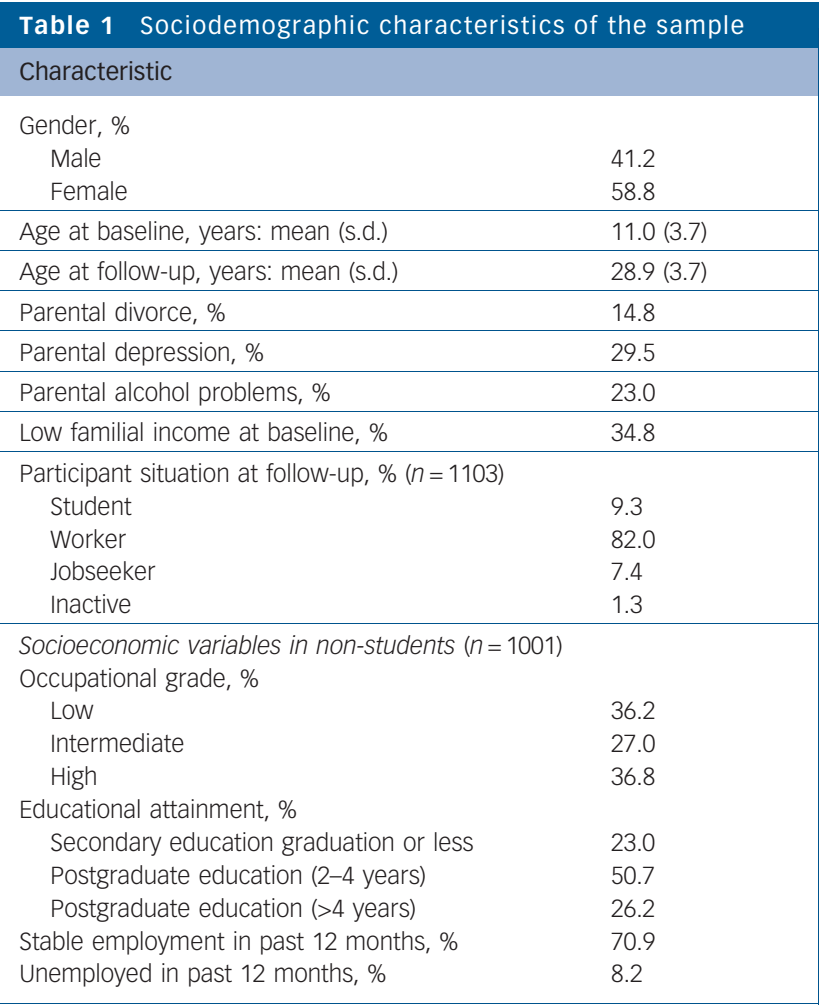

\section{Comparison with previous findings}

These results based on a community-based sample are in line with prior research conducted in clinical populations. Beyond attention problems, several early risk factors appeared to contribute to socioeconomic disadvantage 18 years later. Nevertheless, except for family income at baseline, they were less strongly associated with the study outcome than attention problems. Consistent with prior research, externalising problems were associated with subsequent low socioeconomic status. ${ }^{18}$ This association may be

Table 2 Situation and socioeconomic status at follow-up categorised by level of childhood attention problems

\begin{tabular}{|c|c|c|c|}
\hline & \multicolumn{2}{|c|}{ Attention problems centile group } & \multirow[b]{2}{*}{$P$} \\
\hline & $\begin{array}{c}\text { At or above 90th centile } \\
\%\end{array}$ & $\begin{array}{c}\text { Below 90th centile } \\
\%\end{array}$ & \\
\hline \multicolumn{4}{|l|}{ Participant situation at follow-up ( $(n=1103)$} \\
\hline Student & 4.6 & 9.8 & 0.0007 \\
\hline Worker & 79.7 & 82.6 & \\
\hline Jobseeker & 11.1 & 6.8 & \\
\hline Inactive & 4.6 & 0.8 & \\
\hline \multicolumn{4}{|c|}{ Socioeconomic variables in non-students $(n=1001)$} \\
\hline \multicolumn{4}{|c|}{ Occupational grade } \\
\hline Low & 57.0 & 33.7 & $<0.0001$ \\
\hline Intermediate & 23.2 & 27.3 & \\
\hline High & 19.8 & 39.0 & \\
\hline \multicolumn{4}{|l|}{ Educational attainment } \\
\hline Secondary education graduation or less & 46.0 & 20.4 & $<0.0001$ \\
\hline Postgraduate education ( $2-4$ years) & 44.0 & 51.5 & \\
\hline Postgraduate education ( $>4$ years) & 10.0 & 28.1 & \\
\hline Stable employment in past 12 months & 71.5 & 71.0 & NS \\
\hline Unemployed in past 12 months & 12.2 & 7.7 & NS \\
\hline \multicolumn{4}{|l|}{ Socioeconomic status (overall indicator) } \\
\hline Low & 48.4 & 29.9 & $<0.0001$ \\
\hline Intermediate & 37.9 & 36.7 & \\
\hline High & 13.7 & 33.4 & \\
\hline
\end{tabular}




\begin{tabular}{|c|c|c|c|c|c|c|}
\hline & \multicolumn{6}{|c|}{ Odds ratio $(95 \% \mathrm{Cl})$} \\
\hline & \multicolumn{3}{|c|}{ Model $1^{a}$} & \multicolumn{3}{|c|}{ Model $2^{\mathrm{b}}$} \\
\hline & High SES & Intermediate SES & LOW SES & High SES & Intermediate SES & LOW SES \\
\hline \multicolumn{7}{|l|}{ CBCL problems } \\
\hline Attention & 1.0 & $2.86(1.48-5.54)$ & $4.66(2.50-8.69)$ & 1.0 & $2.43(1.23-4.81)$ & $3.44(1.72-6.92)$ \\
\hline Externalising & 1.0 & $1.95(1.07-3.58)$ & $2.69(1.48-4.91)$ & 1.0 & $1.68(0.89-3.21)$ & $2.11(1.10-4.05)$ \\
\hline Internalising & 1.0 & $1.07(0.63-1.84)$ & $1.45(0.83-2.52)$ & 1.0 & - & - \\
\hline \multicolumn{7}{|l|}{ Familial variables } \\
\hline Low income & 1.0 & $2.54(1.72-3.76)$ & $4.11(2.70-6.26)$ & 1.0 & $2.45(1.65-3.64)$ & $3.77(2.45-5.81)$ \\
\hline Intermediate income & 1.0 & $1.78(1.21-2.63)$ & $2.14(1.40-3.27)$ & 1.0 & $1.73(1.17-2.57)$ & $2.07(1.34-3.19)$ \\
\hline Parental divorce & 1.0 & $1.35(0.83-2.19)$ & $2.28(1.41-3.67)$ & 1.0 & $1.15(0.70-1.89)$ & $1.78(1.08-2.93)$ \\
\hline Parental alcohol problems & 1.0 & $1.52(1.04-2.21)$ & $1.70(1.15-2.52)$ & 1.0 & $1.44(0.98-2.13)$ & $1.61(1.07-2.45)$ \\
\hline Parental depression & 1.0 & $0.96(0.67-1.36)$ & $1.16(0.81-1.67)$ & 1.0 & - & - \\
\hline
\end{tabular}

related to school failure, other frequent comorbidities such as substance use disorders and non-compliance to rules and structured activities in the workplace. Additionally, with the exception of internalising problems that were not associated with subsequent socioeconomic disadvantage, we found that family characteristics including low household income, parental divorce and parental alcohol-related problems predicted subsequent socioeconomic disadvantage, but did not account for the association between symptoms of attention problems and poor adult outcomes.

\section{Putative mechanisms of association}

Attention-deficit hyperactivity disorder could be linked to socioeconomic disadvantage through several pathways. At an early stage, ADHD is likely to contribute to academic underachievement through grade retention, need for special education and low academic achievement. The association between ADHD and such academic problems could be due to children's behavioural symptoms but also to other possible comorbid cognitive features, learning disabilities or language disorders. Interestingly, as suggested by other studies, the negative relationship between ADHD and academic attainment remains after accounting for IQ score, socioeconomic status and comorbid disorders. ${ }^{5,31}$ Since academic underachievement adversely influences employment and educational possibilities, it is a potential mediator of the association between ADHD and socioeconomic status.

At a later stage, numerous features associated with ADHD, some of which persist even after attention problems decrease with age, are potentially related to workplace problems and workrelated anxiety. Indeed, ADHD could lead to an inability to achieve the necessary skills to comply with job expectations, leading to poor work performance and difficulties in relationships with colleagues. ${ }^{32}$ First, ADHD core symptoms of inattention, poor concentration, distractibility, motor hyperactivity and impulsivity may have a direct role in the occurrence of workplace difficulties. They could affect work performance and cooperation with colleagues through an inability to fulfil key work tasks, failure to remember or listen to instructions, excessive verbal or motor activity, and failure to inhibit responses. Second, the socio-emotional impairments found in ADHD, such as poor self-regulation of emotions (emotional impulsiveness) and lack of empathy, may hamper social exchanges at work, leading to poor cooperation, turn-taking and sharing, and conflicts with colleagues. $^{33,34}$ Third, executive function deficits, which characterise $30-50 \%$ of people with $\mathrm{ADHD},{ }^{35}$ may compound workplace difficulties in addition to ADHD symptoms themselves. In fact, executive function deficits exhibit compromised response inhibition, working memory (particularly non-verbal and manipulative aspects) and planning. All these dysfunctions jeopardise the ability to solve problems and self-organise, leading to increased confusion in decision-making. ${ }^{33,36,37}$ Fourth, other neuropsychological impairments associated with ADHD, such as delay aversion, difficulties in self-motivation and timing deficits, may also have negative consequences at work. ${ }^{37,38}$ Inability to maintain an effort over immediate satisfaction $v$. more delayed consequences and poor cross-temporal organisation undermine the capacity to initiate and maintain behaviour across time, an ability that is often needed in job tasks. Finally, other consequences and associated characteristics of ADHD such as poor self-esteem and adult psychiatric comorbidity (anxiety, depression, antisocial behaviours, substance use disorders and personality disorders) may induce functional impairment and maladjustment in job activities. However, in adults with ADHD it has been suggested that most of the time out of role could be imputed to ADHD itself rather than to co-occurring disorders. ${ }^{7}$

\section{Strengths and limitations}

The main strengths of this study are its community-based sample and the longitudinal follow-up over an 18-year period. However, its limitations should be considered when interpreting the findings. First, we used CBCL scores as proxies of psychiatric disorder. This precluded consideration of functional impairment, symptom duration and ADHD subtypes. Nevertheless, CBCL scales have high levels of validity when compared with DSM clinical diagnoses, ${ }^{24}$ which implies that symptoms identified with this instrument have clinical significance. Second, attrition was high in this longitudinal data-set. Reassuringly, comparisons between participants and non-participants in 2009 did not show any significant difference regarding parental and youth psychopathology, implying that non-response did not induce any significant bias in relation to these characteristics. Third, selective attrition occurred since individuals with low socioeconomic status at baseline were underrepresented because participants came from families where one parent had high job security, and families with a higher socioeconomic status were more likely to participate in the follow-up. This may have biased the study towards less severe cases and consequently might have produced more conservative results. Fourth, we did not consider 
other potential confounding factors such as ADHD symptoms at follow-up, IQ levels, learning disability, executive dysfunction, bipolar disorder, child maltreatment, biological factors, parental ADHD and treatment status. However, this sample is unlikely to have been exposed to psychostimulant medication owing to the setting in France and the time period.

\section{Implications}

Attention-deficit hyperactivity disorder appears to be a potent early risk factor for subsequent low socioeconomic position. Since $\mathrm{ADHD}$ is a frequent chronic disorder, taking it into account early on could help diminish the long-term impairment reflected in deleterious socioeconomic trajectories. In addition, early detection of academic difficulties in children with ADHD could serve to implement school support and specific remediation programmes, which could help improve children's academic performances. ${ }^{39}$ Vocational assessment and work preparation could also be worthwhile before academic and occupational pursuit and orientation. Clinicians, parents, teachers and career counsellors should help youths and adults with ADHD choose academic and occupational tracks that match their strengths and weaknesses. ${ }^{2,40}$

At a later stage, consideration of ADHD problems in the workplace might be fruitful. Better identification of adults with undiagnosed ADHD could benefit them not only through adequate individual interventions but also through occupational adjustment to optimise their abilities and minimise their difficulties in their job function and environment. Interestingly, self-rating of executive functioning, which appears more predictive of impairment in occupational functioning than executive function tests, could help in identifying difficulties in adults with $\mathrm{ADHD}^{33}$ Such tools could help in assessing individuals most at risk of work failure and serve to identify specific targets for remediation. However, studies of the cost-effectiveness of such procedures are needed. Finally, another important area deserving attention is colleagues' and managers' social representations. Informing them about ADHD might transform their views of their affected colleagues and lead to a more tolerant, socially harmonious and efficient workplace.

Cédric Galéra, Child and Adolescent Psychiatry Department, University of Bordeaux and Institut National de la Santé et de la Recherche Médicale (INSERM) U897, Centre for Research in Epidemiology and Biostatistics, and Charles Perrens Hospital, Bordeaux, France: Manuel-Pierre Bouvard, Child and Adolescent Psychiatry Department, University of Bordeaux, and Charles Perrens Hospital, Bordeaux, France: Emmanuel Lagarde, INSERM U897, Centre for Research in Epidemiology and Emmanuel Lagarde, INSERM U897, Centre for Research in Epidemiology and Biostatistics, BordeauX, France; Gregory Michel, Laboratory of Psychology, Health
and Quality of Life, University of Bordeaux; Evelyne Touchette, INSERM U1018, Centre for Research in Epidemiology and Population Health, Villejuif, University of Versailles Saint-Quentin, Villejuif, France, and Research Unit on Children's Psychosocial Maladjustment, Department of Psychology, Laval University, Quebec Canada; Eric Fombonne, McGill University, Montreal Children's Hospital, Child Psychiatry, Montreal, Canada; Maria Melchior, INSERM U1018, Centre for Research in Epidemiology and Population Health, and University of Versailles Saint-Quentin, Villejuif, France

Correspondence: Cédric Galéra, University Bordeaux Segalen, INSERM U897, France.Email: cedric.galera@u-bordeaux2.fr

First received 7 Sep 2011, final revision 25 Jan 2012, accepted 22 Feb 2012

\section{References}

1 Polanczyk G, Silva de Lima M, Lessa Horta B, Biederman J, Rohde LA. The worldwide prevalence of ADHD: a systematic review and metaregression analysis. Am J Psychiatry 2007; 164: 942-8.

2 Barkley RA, Fischer M, Smallish MA, Fletcher K. Young adult outcome of hyperactive children: adaptive functioning in major life activities. J Am Acad Child Adolesc Psychiatry 2006; 45: 192-202.
3 Bernfort L, Nordfeldt S, Persson J. ADHD from a socio-economic perspective. Acta Paediatr 2008; 97: 239-45.

4 Biederman J, Faraone SV, Spencer TJ, Mick E, Monuteaux MC, Aleardi M. Functional impairments in adults with self-reports of diagnosed ADHD: a controlled study of 1001 adults in the community. J Clin Psychiatry 2006; 67 524-40.

5 Galéra C, Melchior M, Chastang JF, Bouvard MP, Fombonne E. Hyperactivityinattention symptoms in childhood and adolescence and academic outcomes 8 years later: the Youth Gazel Cohort. Psychol Med 2009; 39: 1895-906.

6 Mannuzza S, Klein RG. Long-term prognosis in attention-deficit/hyperactivity disorder. Child Adolesc Psychiatr Clin N Am 2000; 9: 711-26.

7 De Graaf R, Kessler RC, Fayyad J, ten Have M, Alonso J, Angermeyer M, et al. The prevalence and effects of adult attention-deficit/hyperactivity disorder (ADHD) on the performance of workers: results from the WHO World Mental Health Survey Initiative. Occup Environ Med 2008; 65: 835-42.

8 Kessler RC, Adler L, Ames M, Barkley RA, Birnbaum H, Greenberg P, et al. The prevalence and effects of adult attention deficit/hyperactivity disorder on work performance in a nationally representative sample of workers. $J$ Occup Environ Med 2005; 47: 565-72.

9 Kessler RC, Lane M, Stang PE, Van Brunt DL. The prevalence and workplace costs of adult attention deficit hyperactivity disorder in a large manufacturing firm. Psychol Med 2009; 39: 137-47.

10 Dirks MA, Boyle MH, Georgiades K. Psychological symptoms in youth and later socioeconomic functioning: do associations vary by informant? J Clin Child Adolesc Psychol 2011; 40: 10-22.

11 Muntaner C, Eaton WW, Miech R, O'Campo P. Socioeconomic position and major mental disorders. Epidemiol Rev 2004; 26: 53-62.

12 wadsworth ME, Achenbach TM. Explaining the link between low socioeconomic status and psychopathology: testing two mechanisms of the social causation hypothesis. J Consult Clin Psychol 2005; 73: 1146-53.

13 Hjern A, Weitoft GR, Lindblad F. Social adversity predicts ADHD-medication in school children - a national cohort study. Acta Paediatr 2010; 99: 920-4.

14 Amone-Polak K, Burger $\mathrm{H}$, Ormel J, Huisman M, Verhulst FC, Oldehinkel AJ. Socioeconomic position and mental health problems in pre- and earlyadolescents: the TRAILS study. Soc Psychiatry Psychiatr Epidemiol 2009; 44 231-8.

15 Melchior M, Moffitt TE, Milne BJ, Poulton R, Caspi A. Why do children from socioeconomically disadvantaged families suffer from poor health when they reach adulthood? A life-course study. Am J Epidemiol 2007; 166: 966-74.

16 Melchior M, Chastang JF, Walburg V, Galéra C, Fombonne E. Family income and youths' symptoms of depression and anxiety: a longitudinal study of the GAZEL Youth cohort. Depress Anxiety 2010; 27: 1095-103.

17 Galéra C, Côté SM, Bouvard MP, Pingault JB, Melchior M, Michel G, et al. Early risk factors of hyperactivity-impulsivity and inattention trajectories from 17 months to 8 years. Arch Gen Psychiatry 2011; 68: 1267-75.

18 Colman I, Murray J, Abbott RA, Maughan B, Kuh D, Croudace TJ, et al. Outcomes of conduct problems in adolescence: 40 year follow-up of national cohort. BMJ 2009; 338: a2981.

19 Johnson JG, Cohen P, Dohrenwend BP, Link BG, Brook JS. A longitudinal investigation of social causation and social selection processes involved in the association between socioeconomic status and psychiatric disorders. J Abnorm Psychol 1999; 108: 490-9.

20 Fombonne E, Vermeersch S. Children of the GAZEL Cohort: I. Prevalence of contacts with the medicoeducational system for psychological reasons, and associated factors. Rev Epidemiol Sante Publ 1997; 45: 29-40.

21 Goldberg M, Leclerc A, Bonenfant S, Chastang JF, Shmaus A, Kaniewski N, et al. Cohort profile: the GAZEL cohort study. Int J Epidemiol 2007; 36: 32-9.

22 Achenbach TM. Manual for the Child Behavior Checklist 4-18 and 1991 Profile. Department of Psychiatry, University of Vermont, 1991.

23 Institut National de la Statistique et des Etudes Economiques. Diplôme le plus élevé selon le sexe et l'âge. INSEE, 2007 (http://www.insee.fr/fr/themes/ tableau.asp?reg_id=0\&ref_id=NATCCF07235).

24 Achenbach TM, Dumenci L, Rescorla LA. DSM-oriented and empirically based approaches to constructing scales from the same item pools. J Clin Child Adolesc Psychol 2003; 32: 328-40.

25 Fombonne E. The Chartres Study: I. Prevalence of psychiatric disorders among French school-age children. Br J Psychiatry 1994; 164: 69-79.

26 Biederman J, Faraone SV, Doyle A, Krifcher Lehman B, Kraus I, Perrin J, et al. Convergence of the Child Behavior Checklist with structured interview-based psychiatric diagnoses of ADHD children with and without comorbidity. J Child Psychol Psychiatry 1993; 34: 1241-51.

27 Maxwell ME. Family Interview for Genetic Studies (FIGS): A Manual for FIGS. Clinical Neurogenetics Branch, Intramural Research Program, National Institute of Mental Health, 1992. 
28 Hanson MD, Chen E. Socioeconomic status and health behaviors in adolescence: a review of the literature. J Behav Med 2007; 30: 263-85.

29 Institut National de la Statistique et des Etudes Economiques. Taux de chômage par tranche d'âge. INSEE, 2006 (http://www.insee.fr/fr/ffc/chifcle fiche. asp? ref id=NATCCF03302\&tab id=313\&souspop=1).

30 Lynch J, Kaplan GA. Socioeconomic position. In Social Epidemiology (eds LF Berkman, I Kawachi): 13-35. Oxford University Press, 2000.

31 Polderman TJ, Boomsma DI, Bartels M, Verhulst FC, Huizink AC. A systematic review of prospective studies on attention problems and academic achievement. Acta Psychiatr Scand 2010; 122: 271-84.

32 Biederman J, Mick E, Fried R, Aleardi M, Potter A, Herzig K. A simulated workplace experience for nonmedicated adults with and without ADHD. Psychiatr Serv 2005; 56: 1617-20.

33 Barkley RA, Murphy KR. Impairment in occupational functioning and adult ADHD: the predictive utility of executive function (EF) ratings versus EF tests. Arch Clin Neuropsychol 2010; 25: 157-73.

34 Barkley RA. Major life activity and health outcomes associated with attention-deficit/hyperactivity disorder. J Clin Psychiatry 2002; 63: 10-5.
35 Nigg JT, Willcutt EG, Doyle AE, Sonuga-Barke EJ. Causal heterogeneity in attention-deficit/hyperactivity disorder: do we need neuropsychologically impaired subtypes? Biol Psychiatry 2005; 57: 1224-30.

36 Biederman J, Petty C, Fried R, Fontanella J, Doyle AE, Seidman L, et al. Impact of psychometrically defined deficits of executive functioning in adults with attention deficit hyperactivity disorder. Am J Psychiatry 2006; 163: $1730-8$.

37 Sonuga-Barke EJ, Sergeant JA, Nigg J, Willcutt E. Executive dysfunction and delay aversion in attention deficit hyperactivity disorder: nosologic and diagnostic implications. Child Adolesc Psychiatr Clin N Am 2008; 17: 367-84.

38 Querne L, Berquin P. Distinct response time distributions in attention deficit hyperactivity disorder subtypes. J Atten Disord 2009; 13: 66-77.

39 Raggi VL, Chronis AM. Interventions to address the academic impairment of children and adolescents with ADHD. Clin Child Fam Psychol Rev 2006; 9: 85-110.

40 Nadeau KG. Career choices and workplace challenges for individuals with ADHD. J Clin Psychol 2005; 61: 549-63.

\section{The Adjudicator of Pain}

\section{Ron Charach}

"Forget what you know about pain," says the specialist

from the mansion across the false creek

"think nociceptive verses neuropathic

and you're never far away from the truth."

He assesses for insurance companies;

it's lucrative work paying three times the government-funded rate.

He boasts a two-million-dollar fund

he can access for the most desperate cases,

but he lets slip that it's the minor accidents

with the greatest apparent disability

that he has no patience with,

the "chronic-fatigue/fibromyalgia types."

"They're intent on defeating

any helpful suggestion;

they embrace their pain

rather than fight it, you know?"

I don't think I do.

How many just claims does he

unfairly dismiss

for those premium-collecting firms?

How many souls are left

outside the gates of mercy? Suffering

and wondering themselves how they ended up

where every sentence that begins with

Forget what you know about pain

end up - far away from the truth.

Ron Charach took his medical degree at the University of Manitoba, Canada. He trained in psychiatry in Toronto and New York, and has lived in Toronto since 1980. Dr Charach is the author of nine books of poetry and the non-fiction book Cowboys and Bleeding Hearts: Essays on Violence, Health and Identity. This poem is from his new volume of poetry Forgetting the Holocaust, published in Calgary, Alberta, by Frontenac House (2011). (c) Ron Charach.

Chosen by Femi Oyebode. 